\title{
Effect of analgesia during hoof trimming on gait, weight distribution, and activity of dairy cattle
}

\author{
N. Chapinal, ${ }^{* 1}$ A. M. de Passillé, $†$ J. Rushen, $†$ and S. A. Wagnerł \\ *Animal Welfare Program, University of British Columbia, 2357 Main Mall, Vancouver, BC, V6T 1Z4, Canada \\ †Agriculture and Agri-Food Canada, PO Box 1000, Agassiz, BC, V0M 1A0, Canada \\ ‡Department of Animal Sciences, PO Box 6050, North Dakota State University, Fargo 58108
}

\section{ABSTRACT}

Sixty-six lactating cows were either injected with flunixin meglumine $(2.2 \mathrm{mg} / \mathrm{kg}$ of $\mathrm{BW})$ immediately before hoof trimming $(\mathrm{n}=28)$, injected with a saline solution immediately before hoof trimming $(\mathrm{n}=28)$, or injected with a saline solution immediately before sham hoof trimming (control; $\mathrm{n}=10$ ). Gait scores, time spent lying down, frequency of steps, and how cows distributed their weight among their legs when standing before, during, and after injections were measured to assess whether automated measures of activity and weight distribution can detect lameness and the effects of pain mitigation during hoof trimming. The overall gait score was positively correlated with the variability of the weight applied the rear legs $(r=0.32)$ and negatively correlated with the rear leg weight ratio (LWR; $\mathrm{r}=-0.52)$ and the frequency of steps $(\mathrm{r}=-0.43)$. The rear LWR was the best predictor of cows being lame (NRS >3), accounting for $27 \%$ of the variation in the likelihood of a cow being lame and $11 \%$ of the variation in the likelihood of a cow having an infectious hoof lesion. For each 5\% increase in the rear LWR, the likelihood of being lame decreased by $30 \%$ (odds ratio $=0.71 ; 95 \%$ confidence interval $=0.56,0.90)$ and the likelihood of being afflicted with an infectious hoof disease decreased by $20 \%$ (odds ratio $=0.81 ; 95 \%$ confidence interval $=0.67,0.98)$. Neither hoof trimming nor a combination of hoof trimming and analgesia significantly affected gait score or any measure of weight distribution. Daily lying time increased during the $2 \mathrm{~d}$ following hoof trimming independently of the flunixin meglumine injection. However, this increase was not sustained for longer than $2 \mathrm{~d}$ when cows were injected with flunixin meglumine. Measures of weight shifting between legs while cows are standing and measures of activity show great potential as automated methods of detecting lameness and may also provide a tool for

Received December 11, 2009.

Accepted March 15, 2010.

${ }^{1}$ Corresponding author: nchapinal@yahoo.com future evaluation of lameness therapies, such as hoof trimming and pain mitigation.

Key words: lameness, weight distribution, lying behavior, step

\section{INTRODUCTION}

Lameness is prevalent in modern dairy herds (Cook, 2003; Espejo et al., 2006) and has detrimental effects on productivity and animal welfare. Unfortunately, producers find it difficult to identify animals at the early stages of lameness (Whay et al., 2003; Espejo et al., 2006). In large herds, automatic methods of lameness detection are gaining interest. Lameness in cows is apparent in a change in the way that cows distribute their weight among their 4 legs when standing (Pastell and Kujala, 2007; Chapinal et al., 2010; Pastell et al., 2010), as well as in reduced activity levels, such as more time lying down (O'Callaghan et al., 2003; Chapinal et al., 2009b) or reduced mobility (Borderas et al., 2008). These behavioral changes can be monitored automatically.

When animals are treated by veterinarians for the underlying cause of lameness, they often receive limited or no treatment for the accompanying pain. Nonsteroidal antiinflammatory drugs (NSAID), such as ketoprofen or flunixin meglumine, are proven analgesics approved for use in lactating dairy cows in Canada and the United States, respectively. Ketoprofen has been recommended as a means of pain mitigation during the treatment of lameness in dairy cows (O'Callaghan, 2002) and has been shown to moderately improve gait score in lame cows (Flower et al., 2008). However, we know little about how pain mitigation reduces the effects of lameness on other behaviors, such as the activity levels of the cows.

Hoof trimming remains the most widely used method available to producers to control and treat lameness in cattle. Despite its extensive use, few controlled studies have investigated the effectiveness of hoof trimming or its effect on locomotion and lameness in dairy cattle. Studies report that long intervals between hoof trimming 
or a lack of routine hoof trimming are associated with increased risks of lameness and hoof lesions (Manske et al., 2002; Somers et al., 2005). Although these studies provide some evidence for the long-term advantages of routine hoof trimming, they do not allow us to determine whether the effect is preventive or curative, nor do they provide information about the short-term effects of hoof-trimming on cows' gait. Some experimental studies have looked at short-term effects and have shown that good hoof trimming improves traction between the hoof and the floor (Phillips et al., 2000) and weight bearing by the hoof (van der Tol et al., 2004). In contrast, other studies show the reverse and suggest that routine hoof trimming is associated with poorer hoof health of cows (Fjeldaas et al., 2006; Barker et al., 2007). De Passillé and Rushen (2006) also noted deterioration in gait following routine hoof trimming. Improper hoof trimming has long been recognized as a contributing factor to lameness in dairy cows (Shearer and van Amstel, 2001) and recent surveys of the effectiveness of hoof trimming continue to raise concerns about the skill with which the trimming is done (Fjeldaas et al., 2006). Overall, there is a lack of evidence for the potential curative role of hoof trimming in the treatment of animals identified as being lame. Furthermore, little information is available on how hoof trimming affects cows' overall gait or general levels of rest and activity.

The advantages of pain control during hoof trimming have not been evaluated. Cortisol levels (often a sign of stress) were found to increase after hoof trimming, suggesting that cows find it painful or stressful (Reinemann et al., 1999). Therefore, the use of a NSAID as a palliative treatment in conjunction with hoof trimming may reduce pain and suffering related to lameness and to the possible pain during and immediately after hoof trimming.

The objective of this study was to assess gait and automated measures of weight distribution among the legs and of daily activity as methods for 1) detecting lameness in dairy cows and 2) measuring the effects of pain mitigation during hoof trimming.

\section{MATERIALS AND METHODS}

\section{Animals and Housing}

We selected 66 lactating Holstein cows (parity $=2.4$ $\pm 1.4 ; \mathrm{BW}=644 \pm 68 \mathrm{~kg} ; \mathrm{DIM}=377 \pm 149 ; 305-\mathrm{d}$ milk production $=23,366 \pm 3,802 \mathrm{~kg}$ ) from a commercial herd of 500 milking cows in west-central Minnesota. Cows were housed in sand-bedded free-stalls in groups of approximately 100 cows/pen. Cows were fed a TMR diet once daily at $1000 \mathrm{~h}$ that was formulated to meet requirements for lactating dairy cows (NRC, 2001).
Water was freely available from self-filling troughs. Lactating cows were milked twice daily in the parlor at 1000 and $2200 \mathrm{~h}$ for the first half of the project, at which time the farm protocol changed and cows were milked 3 times daily at 0200, 1000, and $1800 \mathrm{~h}$. All procedures involving animals were approved by the Institutional Animal Care and Use Committee at North Dakota State University.

\section{Experimental Procedure and Treatments}

For a period of $11 \mathrm{wk}$, a subset of at least 6 animals/ wk was selected from 1 of 2 different pens, each of which housed approximately 100 cows of the same stage of lactation and under the same management protocols. The day before treatments were applied, cows were gait scored using a 1-to-5 numerical rating system (NRS; where $1=$ perfect gait and $5=$ severely lame) following Flower and Weary (2006) and Chapinal et al. (2009b). Each animal was randomly assigned to 1 of 3 treatments: flunixin meglumine (Banamine, Schering-Plough Animal Health, Union, NJ) injected immediately before hoof trimming (FMHT; $\mathrm{n}=28$ ); saline injected immediately before hoof trimming (SLHT; $\mathrm{n}=28$ ); or saline injected immediately before sham hoof trimming (control; $\mathrm{n}=10$ ). Animals were assigned such that treatment groups were balanced according BW, parity, and DIM. Treatments FMHT and SLHT were assigned according to initial gait score, maximizing the range of scores. For ethical reasons, only nonlame cows (NRS $\leq 3)$ were assigned to the control treatment. Between 2 and 4 cows were assigned to FMHT and SLHT treatments every week, whereas 2 cows were assigned to the control treatment on 5 of the 11 experimental weeks.

Immediately following the initial gait score and weight recordings, cows were moved together to another group pen with sand-bedded free stalls with other nonexperimental cows and fed the same ration as other lactating cows. On 2 consecutive days, cows were held in a headlock and the dose of $2.2 \mathrm{mg}$ of flunixin meglumine/ $\mathrm{kg}$ of $\mathrm{BW}$ or the equivalent volume $(1 \mathrm{~mL} / 22.7 \mathrm{~kg}$ of BW) of saline solution was injected intravenously in the neck. All cows were treated at 24-h intervals, and immediately after the first injection cows were restrained in a tilt chute and hoof trimmed by a professional hoof trimmer who recorded the presence of hoof lesions. Routine hoof trimming was performed to promote correct weight bearing by reshaping the claw capsule. In the case that cows were afflicted with sole ulcer, the damaged horn was pared away to allow formation and growth of new horn. In the case of abscess, underrun horn was removed to facilitate drainage. Control cows were restrained in the tilt chute for 5 min (estimated average hoof trimming time), manure was scraped from 
their hoof soles, and hooves were examined to assess hoof health. All cows returned to their home pen after the final gait scores and weight distribution measurements were recorded.

\section{Data Collection}

Gait Score. The cows were gait scored at a fixed time of the day on the day before treatment, on the $2 \mathrm{~d}$ of treatment ( $2 \mathrm{~h}$ after the injections), and on the day after treatment.

Cows' gaits were scored from video taken while they were walking down a nongrooved concrete passageway (20 m long $\times 4 \mathrm{~m}$ wide). To encourage cows to walk in a consistent manner, a handler walked immediately behind the cows encouraging them when necessary. Cows had been habituated to the procedure by repeatedly walking them down the passageway for at least 3 passages on a day before gait scoring began. On data collection days, each cow was videotaped during each of 3 passages/d from her right side with a color digital camera (Canon ZR70MC Digital Camcorder, Canon, Lake Success, NY) placed $8 \mathrm{~m}$ from the cow to allow recording of at least 4 complete strides during each passage. An experienced observer who was masked to treatment group assignments watched the videos and assigned a gait score to each cow for each day by using a 1-to-5 NRS as described by Flower and Weary (2006) and Chapinal et al. (2009b). If a cow exceeded the requirements of a particular score, a half-integer score was allocated. Overall gait was also assessed by using a continuous 100-unit visual analog scale (VAS; Flower and Weary, 2006).

Weighing Platform. Measures of how the cows distributed their weight among their legs while standing were taken using the method described in Chapinal et al. (2009a). This was done on the day before treatment, on the $2 \mathrm{~d}$ of treatment, and on the day after treatment.

The distribution of weight among the legs was measured while cows were standing on a weighing platform (Pacific Industrial Scale Co. Ltd., Richmond, British Columbia, Canada) situated at the end of the passageway used for gait scoring (Chapinal et al., 2010). The platform contained 4 stainless steel independent recording units $(12 \mathrm{~cm}$ high $\times 59 \mathrm{~cm}$ wide $\times 99 \mathrm{~cm}$ long $)$ covered with textured rubber mats $(1.5 \mathrm{~cm}$ thick). Each recording unit contained 4 stainless steel load cells, hermetically sealed cells (3mV Shear Beam Load cells, Anyload LLC, Santa Rosa, CA; maximum capacity = $454 \mathrm{~kg} / \mathrm{load}$ cell). The weights recorded were always the same regardless of the position of the hooves on the units. Data were transmitted to a computer at a rate of
14 readings/s. Specific software (CowWeigh version 2.2, Pacific Industrial Scale Co. Ltd.) was used to provide a real-time display of the weight applied to each of the 4 units. The platform was lifted $4.5 \mathrm{~cm}$ from the floor with concrete blocks to avoid load cell corrosion caused by humidity. A manual steel squeeze $(2.1 \mathrm{~m}$ high $\times 2.0$ $\mathrm{m}$ long $\times 1.3 \mathrm{~m}$ wide) was mounted on the platform to restrain the cows.

Cows had been familiarized with the platform and the procedure by having them stand on the platform at least 3 times on the day before data collection began. On data collection days, cows stood on the platform for 5 min after each of the 3 walking passages. When hooves were not on the appropriate recording unit, the cow was gently manipulated to encourage repositioning.

Activity. Three days before treatment started, the cows were fitted with accelerometers (Ice Tag, Icerobotics Inc., Edinburgh, UK) to continuously record activity over 9 complete days, with a sampling rate of 16 readings/s (Munksgaard et al., 2006). The Ice Tag device was attached by means of a strap to the right rear leg above the fetlock. If signs of inflammation were present in the right rear leg, the device was attached to the left rear leg. The accelerometers recorded the number of steps, the duration of lying/standing bouts, and the total time spent lying and standing per day.

\section{Clinical Examination of the Hooves}

Cows were grouped into 3 hoof health categories: cows with no visible lesions $(\mathrm{n}=25)$, cows with infectious diseases (digital dermatitis, foot rot; $\mathrm{n}=31$ ), and cows with noninfectious lesions (ulcer and sole abscess; $\mathrm{n}=$ 7). Three cows had both noninfectious and infectious lesions, and they were included in the noninfectious lesions for the analyses because previous literature has reported that ulcers have a greater effect on gait than dermatitis (Chapinal et al., 2009b).

\section{Statistical Analysis}

All statistical analyses were performed with SAS (version 9.1; SAS Institute, 2003) using the cow as the experimental unit. Three cows were removed from the study for handlers' safety reasons and no data are available for them. When examining the effect of hoof lesions, only the differences between cows with no lesions and cows with only infectious disease were tested because of the small number of cows with noninfectious lesions (see below).

Readings from the weighing platform in which the total weight recorded was $5 \%$ above or below the mode 
of the total weight within the passage were discarded (Chapinal et al., 2009a). Readings from each passage were summarized to get the mean weight applied on each leg. Data for each pair of legs (front or rear) were averaged by day and animal for the analysis. In addition, 2 more variables that have been suggested in the literature as indicators of lameness were used: 1) the standard deviation of the weight applied on each leg over the 5-min period as a measure of leg-load variability or weight shifting between legs (Rushen et al., 2007), and 2) the leg weight ratio (LWR) between the lighter and the heavier leg of the front pair and of the rear pair of legs as a measure of asymmetry in weight distribution within each pair of legs (Pastell and $\mathrm{Ku}-$ jala, 2007).

For the analysis of activity data, a day was defined as the 24-h period starting at the time of the first injection. Activity data from the $2 \mathrm{~d}$ when the cows were regrouped (i.e., the $24-\mathrm{h}$ period following the first and last gait and weight distribution data collection) were discarded. Data were then averaged by time period: before treatment $(2 \mathrm{~d})$, during treatment $(2 \mathrm{~d})$, and after treatment $(3 \mathrm{~d})$. Because of technical problems, activity data were available for only 51 cows. Data from the period before treatment were summarized by hour to plot diurnal patterns for descriptive purposes only.

Data collected prior the first injection were used to correlate (PROC CORR) overall gait score (VAS) to the different weight distribution and activity variables. A final regression model (PROC REG) was constructed with predictors that correlated the most to VAS, avoiding the inclusion of highly correlated predictors in the same model. Differences in VAS between cows with no lesions and cows with only infectious disease were assessed by using the contrasts statements within the general linear model procedure (PROC GLM) in a model that also included parity (primiparous or multiparous). Differences in weight distribution and activity measures between cows with no lesions and cows with only infectious disease were assessed similarly in a model that also included VAS as a covariate.

Logistic regression (PROC LOGISTIC) was used to determine the predictive value of the weight distribution variables and activity on whether the cow was classified as lame. Numerical rating system, an ordinal scale, was used to classify cows as lame or nonlame using the cut-off point of NRS $>3$ as suggested by Flower and Weary (2006) and Chapinal et al. (2009b). Visual analog scale and NRS were highly correlated $(r>0.90$ for both Pearson and Spearman correlation; $P<0.001$ ). Logistic models were used first to fit one variable at a time. Variables with $P<0.05$ were used to construct a complete logistic model, avoiding the inclusion of highly correlated predictors in the same model.
To assess the effect of hoof trimming and flunixin meglumine, the initial baseline value of gait scores, weight distribution, and activity measures before treatment were subtracted from the values measured on the following days (or time periods in the case of activity measures). Control cows were compared with SLHT cows, and SLHT cows were compared with FMHT cows on each different day or period by using the contrast statements within PROC GLM, in a model that included week of enrollment as a block and treatment, parity (primiparous or multiparous), and health categories (no lesions, infectious diseases, or noninfectious lesions) as factors. Residuals were examined to verify normality and homogeneity of variances.

\section{RESULTS}

\section{Prediction of Lameness by Weight Distribution and Activity Measures}

The overall gait score (VAS) was positively correlated with the standard deviation of the rear legs $(\mathrm{r}=0.32$; $P=0.01$ ) and negatively correlated with the rear LWR $(\mathrm{r}=-0.52 ; P=0.002)$ and the frequency of steps $(\mathrm{r}=$ $-0.43 ; P<0.001$ ). Figure 1 shows the diurnal pattern of the frequency of steps for lame (NRS $>3$ ) and nonlame cows when cows where milked 2 and 3 times daily. The standard deviation of the rear legs and the rear LWR were correlated $(\mathrm{r}=-0.29 ; P=0.02)$ and thus included in 2 different regression models also containing the frequency of steps. The model containing the standard deviation of the rear legs and the frequency of steps explained $22 \%$ of the variation in $\operatorname{VAS}\left(\mathrm{R}^{2}=\right.$ $0.22 ; P=0.001)$, whereas the model containing the rear LWR and the frequency of steps explained 38\% of the variation in VAS $\left(\mathrm{R}^{2}=0.38 ; P<0.001\right)$. The rear LWR was the best predictor of cows being lame (NRS $>3$ ), accounting for $27 \%$ of the variation in the likelihood of a cow being lame $\left(\mathrm{R}^{2}=0.27\right)$. For each $5 \%$ increase in the rear LWR, the likelihood of being lame decreased by $30 \%$ (odds ratio $=0.71 ; 95 \% \mathrm{CI}=0.56$, $\left.0.90 ; P_{\text {Wald }}=0.005\right)$.

Cows with infectious diseases had a lower rear LWR than cows without any lesions $(0.75 \pm 0.05$ vs. $0.80 \pm$ $0.03 ; P=0.006)$. For each $5 \%$ increase in the rear LWR, the likelihood of being afflicted with an infectious hoof disease decreased by $20 \%$ (odds ratio $=0.81 ; 95 \% \mathrm{CI}=$ $\left.0.67,0.98 ; P_{\text {Wald }}=0.03\right)$. The rear LWR accounted for $11 \%$ of the variation in likelihood of a cow having an infectious hoof lesion $\left(\mathrm{R}^{2}=0.11\right)$. No differences were found in VAS or any other weight distribution or activity measure between cows with and without infectious hoof diseases $(P>0.1)$. 

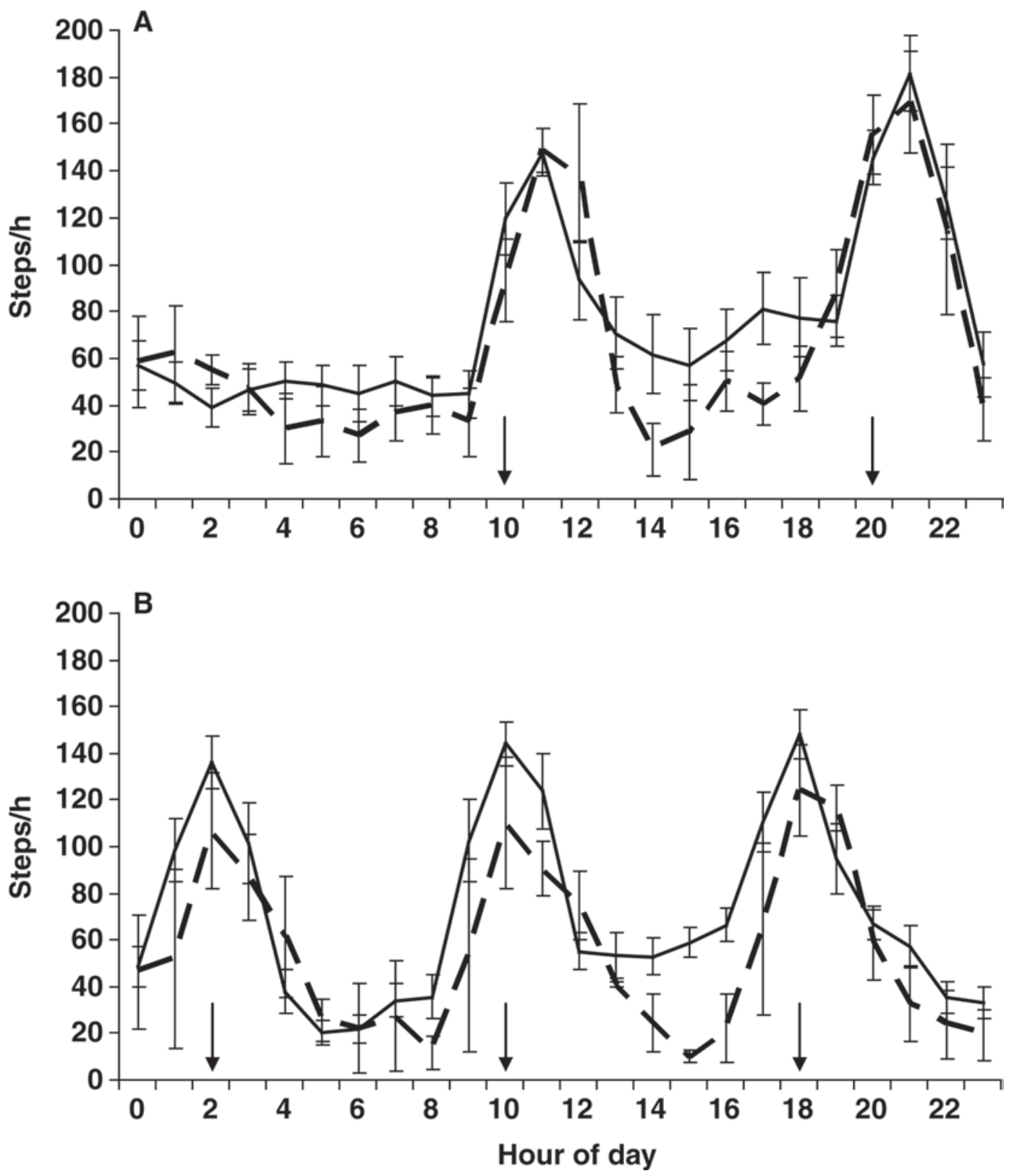

Figure 1. Mean $( \pm \mathrm{SE})$ frequency of steps/h for lame ( $>3$ on a 1-to-5 numerical rating system; $\mathrm{n}=41$; dashed lines $)$ and nonlame $(\mathrm{n}=10$; solid lines) cows housed in free-stall barns when they were milked A) 2 times/d (1000 and $2200 \mathrm{~h})$ and B) 3 times/d (0200, 1000, and 1800 h). Arrows indicate milking.

\section{Effect of Hoof Trimming and Flunixin Meglumine on Gait, Weight Distribution, and Activity Measures}

Neither hoof trimming nor a combination of hoof trimming and analgesia significantly affected gait score or any measure of weight distribution. However, control and FMHT cows tended to have a lower standard deviation of the rear legs after hoof trimming or sham hoof trimming compared with SLHT cows (Table 1).
Daily lying time increased during the 2 d following hoof trimming (period 2) independently of the flunixin meglumine injection (Table 2). However, this increase was not sustained for longer than $2 \mathrm{~d}$ when cows were injected with flunixin meglumine, whereas in hooftrimmed cows without analgesic drug treatment, the increased lying time continued through the end of the recording period. There was no effect of parity or health category in the difference between day or period 1 and the rest of days or periods in any case $(P>0.2)$. 
Table 1. Differences between d 1, 2, 3, and $4^{1}$ in overall gait (VAS) and weight distribution measures for the rear legs for cows injected with saline immediately before sham hoof trimming (control; $\mathrm{n}=10$ ), cows injected with saline immediately before hoof trimming (SLHT; $\mathrm{n}=28$ ), and cows injected with flunixin meglumine immediately before hoof trimming (FMHT; $\mathrm{n}=28)^{2}$

\begin{tabular}{lccr}
\hline & \multicolumn{2}{c}{ Difference from pretreatment baseline (day 1) } \\
\cline { 2 - 4 } Item & Day 2 & Day 3 & Day 4 \\
\hline Overall VAS & & & \\
Control & $-2.25 \pm 2.80$ & $0.51 \pm 3.67$ & $-0.44 \pm 4.37$ \\
SLHT & $-0.10 \pm 1.79$ & $2.72 \pm 2.60$ & $2.79 \pm 3.06$ \\
FMHT & $-1.13 \pm 1.96$ & $-1.83 \pm 2.46$ & $1.95 \pm 2.93$ \\
SD of the rear legs & & & \\
Control & $-5.80 \pm 3.19$ & $-1.31 \pm 4.00$ & $0.58 \pm 4.03$ \\
SLHT & $-0.01 \pm 1.99^{*}$ & $-2.07 \pm 2.50$ & $0.70 \pm 2.71$ \\
FMHT & $-4.73 \pm 2.14^{*}$ & $-6.53 \pm 2.77$ & $-1.80 \pm 2.52$ \\
Rear LWR & & & \\
Control & $0.00 \pm 0.04$ & $0.04 \pm 0.05$ & $0.00 \pm 0.05$ \\
SLHT & $-0.03 \pm 0.03$ & $0.02 \pm 0.03$ & $-0.03 \pm 0.04$ \\
FMHT & $0.02 \pm 0.03$ & $0.03 \pm 0.03$ & $-0.04 \pm 0.03$ \\
\hline
\end{tabular}

${ }^{1} \mathrm{D} 1$ : before hoof trimming and injections; $\mathrm{d} 2$ : when cows were injected with flunixin meglumine or saline and hoof trimmed; d 3: when cows were injected again; d 4: when cows were no longer injected.

${ }^{2}$ The SLHT cows were contrasted against control cows, and FMHT cows were contrasted against SLHT cows.

${ }^{3} \mathrm{LWR}=$ leg weight ratio.

$* P<0.10$.

\section{DISCUSSION}

Our results show that measures of weight distribution show promise as an automated method to detect lameness on farm, especially in association with measures of activity, supporting previous findings (Pastell and Kujala, 2007; Rushen et al., 2007; Chapinal et al., 2010). However, we found little evidence that analgesia during hoof trimming changed cow activity, weight distribution, or gait.

We found that gait score was correlated to the standard deviation of weight applied to the rear legs (a measure of weight shifting) and the rear LWR, supporting previous studies (Pastell and Kujala, 2007; Rushen et al., 2007; Chapinal et al., 2010). The rear LWR was the most accurate in identifying lame cows. This measure is an indicator of asymmetry in weight distribution within each pair of legs. Lame cows are reluctant to bear weight on the afflicted leg and therefore they favor the contralateral leg. Chapinal et al. (2010) found that although both the rear LWR and standard deviation of the weight applied to the rear legs were good predictors of lameness, the latter was more accurate. However, Pastell et al. (2010) found that LWR was the most

Table 2. Differences between periods 1,2 , and $3^{1}$ in activity measures for cows injected with saline immediately before sham hoof trimming (control; $\mathrm{n}=10$ ), cows injected with saline immediately before hoof trimming (SLHT; $\mathrm{n}=28$ ), and cows injected with flunixin meglumine immediately before hoof trimming (FMHT; $\mathrm{n}=$ $28)^{2}$

\begin{tabular}{lcc}
\hline & \multicolumn{2}{c}{ Difference from pretreatment baseline (period 1) } \\
\cline { 2 - 3 } Item & Period 2 & Period 3 \\
\hline Daily lying time $(\mathrm{min})$ & & \\
Control & $-35.24 \pm 70.35$ & $-53.67 \pm 47.28$ \\
SLHT & $132.22 \pm 44.77^{*}$ & $57.55 \pm 30.09^{*}$ \\
FMHT & $134.98 \pm 39.51$ & $-7.88 \pm 26.55^{*}$ \\
Duration of the lying bouts (min) & $-0.94 \pm 1.44$ & $-0.68 \pm 0.96$ \\
Control & $-0.96 \pm 1.05$ & $0.70 \pm 0.64$ \\
SLHT & $-1.90 \pm 1.39$ & $-0.45 \pm 0.54$ \\
FMHT & & $-69.65 \pm 171.96$ \\
Frequency of steps (steps/d) & $220.14 \pm 174.62$ & $-103.94 \pm 109.37$ \\
Control & $-30.20 \pm 111.13$ & $42.22 \pm 97.28$ \\
SLHT & $-5.95 \pm 98.06$ & \\
FMHT &
\end{tabular}

${ }^{1}$ Period 1: before hoof trimming and injections; period 2: when cows were injected and hoof trimmed; period 3: when cows were no longer injected.

${ }^{2}$ The SLHT cows were contrasted against control cows, and FMHT cows were contrasted against SLHT cows. $* P<0.10$. 
accurate measure of weight distribution to detect lame cows. Because it is easy to calculate both variables from the data automatically recorded by means of the weighing platform, we suggest that both variables be considered if weight distribution measures are to be used as a tool to predict lameness on farm.

The frequency of steps was the only measure of activity that correlated to gait score, although it was not a good predictor when cows were classified into lame and nonlame. O'Callaghan et al. (2003) also found that lame cows made fewer steps. We did not find any correlation between lying time and gait score, although lame cows have been reported to spend more time lying down daily and had longer lying bouts in other studies (Chapinal et al., 2009b). Variability between cows in lying time and frequency of steps is very high (Ito et al., 2009) and therefore it is sometimes difficult to predict lameness with these measures. We found that most of the steps are associated with milking and, therefore, frequency of steps is highly influenced by the frequency of milkings and distance from the pen to the milking parlor.

We found little effect of providing analgesia during hoof trimming. Daily lying time after hoof trimming increased independently of the use of analgesia. However, this increase continued longer when cows were not treated with analgesic drugs. Increased lying time has been associated with discomfort attributable to lameness (Chapinal et al., 2009b); therefore, these results suggest there may have been some discomfort associated with hoof trimming. Gait score did not change after hoof trimming with or without analgesia. The effects of NSAID on gait have been reported to be absent or mild in previous studies (Whay et al., 2005; Flower et al., 2008).

The effect of analgesia during hoof trimming on measures of weight distribution was not clear. There was a tendency for cows hoof trimmed after being injected with flunixin meglumine to have a decrease in the standard deviation of the rear legs, and this did not occur in the case of cows hoof trimmed without analgesia. However, the magnitude of the decrease was small (less than $5 \mathrm{~kg}$ ). Chapinal et al. (2010) also found a moderate reduction (approximately $10 \mathrm{~kg}$ ) in the standard deviation of the rear legs when lame cows were injected with the NSAID ketoprofen. Rushen et al. (2007) injected local anesthetic lidocaine to injured hooves and found a decrease of the standard deviation of the injured leg and its contralateral of $25 \mathrm{~kg}$ on average (more than $50 \%$ decrease) following the injections. However, cows in that study had a severe lesion in the hoof and were injected with a local anesthetic (rather than a systemic analgesic) that blocks the nerve; therefore, it had specific and localized effect on the lesion identified as the cause of pain. Further research may determine whether changes in gait score and weight distribution after flunixin treatment were undetected because of the magnitude of the analgesic drug effect, the dosing regimen, or some effect of concurrent hoof trimming.

With herds becoming larger and technology more available, a combination of automated methods of lameness detection could become a practical solution for onfarm lameness detection and for monitoring treatment effectiveness and recovery. Measures of weight shifting among legs while cows are standing and measures of activity show great potential as automated methods of detecting lameness and may also provide a tool for future evaluation of lameness therapies, such as hoof trimming and pain mitigation.

\section{ACKNOWLEDGMENTS}

We thank Molly Ronning, Rachael Runck, Gosia Zdanowicz, and the Schlauderaff Dairy. The project was supported by the National Research Initiative of the USDA National Institute of Food and Agriculture, grant number 2008-35204-04607, Global Animal Partnerships Inc., and Agriculture and Agric-Food Canada. We thank IceRobotics Inc. for the loan of some equipment, encouragement, and advice.

\section{REFERENCES}

Barker, Z. E., J. R. Amory, J. L. Wright, R. W. Blowey, and L. E. Green. 2007. Management factors associated with impaired locomotion in dairy cows in England and Wales. J. Dairy Sci. 90:3270-3277.

Borderas, T. F., A. R. Fournier, J. Rushen, and A. M. de Passillé. 2008. Effect of lameness on dairy cows' visits to automatic milking systems. Can. J. Anim. Sci. 88:1-8.

Chapinal, N., A. M. de Passillé, and J. Rushen. 2009a. Weight distribution and gait in dairy cattle are affected by milking and late pregnancy. J. Dairy Sci. 92:581-588.

Chapinal, N., A. M. de Passillé, J. Rushen, and S. Wagner. 2010. Automated methods for the detection of lameness and analgesia in dairy cattle. J. Dairy Sci. 93:2007-2013.

Chapinal, N., A. M. de Passillé, D. M. Weary, M. A. G. von Keyserlingk, and J. Rushen. 2009b. Using gait score, walking speed, and lying behavior to detect hoof lesions in dairy cows. J. Dairy Sci. 92:4365-4374.

Cook, N. B. 2003. Prevalence of lameness among dairy cattle in Wisconsin as a function of housing type and stall surface. J. Am. Vet. Med. Assoc. 223:1324-1328.

de Passillé, A. M., and J. Rushen. 2006. Effects of lameness on activity in dairy cows and the effects of hoof trimming. Page 54 in 40th International Congress of the International Society for Applied Ethology, Bristol, UK. ISAE Scientific Committee.

Espejo, L. A., M. I. Endres, and J. A. Salfer. 2006. Prevalence of lameness in high-producing Holstein cows housed in freestall barns in Minnesota. J. Dairy Sci. 89:3052-3058.

Fjeldaas, T., Å. M. Sogstad, and O. Østerås. 2006. Claw trimming routines in relation to claw lesions, claw shape and lameness in Norwegian dairy herds housed in tie stalls and free stalls. Prev. Vet. Med. 73:255-271. 
Flower, F. C., M. Sedlbauer, E. Carter, M. A. von Keyserlingk, D. J. Sanderson, and D. M. Weary. 2008. Analgesics improve the gait of lame dairy cattle. J. Dairy Sci. 91:3010-3014.

Flower, F. C., and D. M. Weary. 2006. Effect of hoof pathologies on subjective assessments of dairy cow gait. J. Dairy Sci. 89:139146.

Ito, K., D. M. Weary, and M. A. G. von Keyserlingk. 2009. Lying behavior: Assessing within- and between-herd variation in freestall-housed dairy cows. J. Dairy Sci. 92:4412-4420.

Manske, T., J. Hultgren, and C. Bergsten. 2002. The effect of claw trimming on the hoof health of Swedish dairy cattle. Prev. Vet. Med. 54:113-129.

Munksgaard, L., C. G. Reenen, and R. Boyce. 2006. Automatic monitoring of lying, standing, and walking behavior in dairy cattle. J. Dairy Sci. 89(Suppl. 1):309. (Abstr.)

NRC. 2001. Nutrient Requirements of Dairy Cattle. 7th rev. ed. National Research Council, Washington, DC.

O'Callaghan, K. A. 2002. Lameness and associated pain in cattleChallenging traditional perceptions. In Pract. 24:214-219.

O'Callaghan, K. A., P. J. Cripps, D. Y. Downham, and R. D. Murray 2003. Subjective and objective assessment of pain and discomfort due to lameness in dairy cattle. Anim. Welf. 12:605-610.

Pastell, M., L. Hänninen, A. M. de Passillé, and J. Rushen. 2010. Measures of weight distribution of dairy cows to detect lameness and the presence of hoof lesions. J. Dairy Sci. 93:954-960.

Pastell, M. E., and M. Kujala. 2007. A probabilistic neural network model for lameness detection. J. Dairy Sci. 90:2283-2292.

Phillips, C. J., P. C. Chiy, M. J. Bucktrout, S. M. Collins, C. J. Gasson, A. C. Jenkins, and M. J. Paranhos da Costa. 2000. Frictional properties of cattle hooves and their conformation after trimming. Vet. Rec. 146:607-609.
Reinemann, D. J., M. D. Rasmussen, L. G. Sheffield, M. C. Wiltbank, and S. D. LeMire, 1999. Dairy cow response to electrical environment: Part I. Comparison of behavioral to physiological responses; Part II. Comparison of treatments applied during milking. Report to the Minnesota Public Utilities Commission, June 30, 1999.

Rushen, J., E. Pombourcq, and A. M. de Passillé. 2007. Validation of two measures of lameness in dairy cows. Appl. Anim. Behav. Sci 106:173-177.

SAS Institute. 2003. SAS User's Guide. SAS Institute Inc., Cary, NC. Shearer, J. K., and S. R. van Amstel. 2001. Functional and corrective claw trimming. Vet. Clin. North Am. Food Anim. Pract. 17:5372 .

Somers, J. G. C. J., K. Frankena, E. N. Noordhuizen-Stassen, and J. H. M. Metz. 2005. Risk factors for interdigital dermatitis and heel erosion in dairy cows kept in cubicle housing in The Netherlands. Prev. Vet. Med. 71:23-34.

van der Tol, P. P., S. S. van der Beek, J. H. Metz, E. N. NoordhuizenStassen, W. Back, C. R. Braam, and W. A. Weijs. 2004. The effect of preventive trimming on weight bearing and force balance on the claws of dairy cattle. J. Dairy Sci. 87:1732-1738.

Whay, H. R., D. C. Main, L. E. Green, and A. J. Webster. 2003. Assessment of the welfare of dairy cattle using animal-based measurements: Direct observations and investigation of farm records. Vet. Rec. 153:197-202.

Whay, H. R., A. J. F. Webster, and A. E. Waterman-Pearson. 2005. Role of ketoprofen in the modulation of hyperalgesia associated with lameness in dairy cattle. Vet. Rec. 157:729-733. 